\title{
EL LABERINTO, MOTIVO SACRAMENTAL EN TIRSO Y CALDERÓN ${ }^{1}$
}

\author{
Juan Manuel Escudero Baztán / Blanca Oteiza \\ Departamento de Filología \\ Edificio de Bibliotecas \\ GRISO-Universidad de Navarra \\ 31009 Pamplona. Navarra. España \\ jescudero@unav.es / boteiza@unav.es
}

[Anuario calderoniano (ISSN: 1888-8046), vol. extra, 1, 2013, pp. 127-145]

Uno de los espacios privilegiados del mal en los autos sacramentales de Calderón es la presencia del laberinto como símbolo teratológico, cuya construcción deriva de diversas fuentes mitológicas que el dramaturgo emplea a su libre albedrío. Este motivo, en su conjunto, puede tomarse como un buen pretexto para observar un proceso

${ }^{1}$ Este trabajo se enmarca en el Proyecto de Investigación Fundamental «Edición crítica del teatro completo de Tirso de Molina. Tercera fase» (FFI2010-18619/FILO), subvencionado por el Ministerio de Ciencia e Innovación de España.Y también dentro del proyecto de edición de los autos completos (FFI2011-26695) dirigido por I. Arellano financiado por el Ministerio de Ciencia e Innovación de España. Cuenta, a su vez, con el patrocinio de TC-12, en el marco del programa Consolider-Ingenio 2010, CSD2009-00033, del Plan Nacional de Investigación Científica, Desarrollo e Innovación Tecnológica del Gobierno de España. 
de estilización y de compleja orquestación, una reescritura en parte conceptual, que en este caso relaciona estrechamente a Tirso de Molina y su auto sacramental El laberinto de Creta y a El laberinto del mundo calderoniano ${ }^{2}$.

De El laberinto de Creta no se conserva el original autógrafo, aunque sí dos copias manuscritas en la Biblioteca Nacional de España ${ }^{3}$, donde es uniforme la atribución de la autoría a Tirso de Molina. Pero además del nombre del Mercedario, estos manuscritos aportan la fecha del 1 de marzo de 1638, que parece muy probable la de su composición, quizás con miras a su estreno en el Corpus Christi de ese año.

Por su parte Calderón escribió El laberinto del mundo para la fiesta del Corpus de $1654^{4}$, según consta en el autógrafo ${ }^{5}$. El auto presenta dos puntos básicos de interés. El primero está relacionado con la fecha en que Calderón pasa de utilizar dos a cuatro carros en una escenografia cada vez más compleja y rica en soluciones visuales espec-

${ }^{2}$ Este trabajo se complementará con el estudio del motivo en otros autores: recuérdese que Lope de Vega escribió una comedia homónima, citada en la lista de títulos que aparece en la sexta edición de El peregrino en su patria (1618), y que se publicó en la Parte XVI de comedias del Fénix (1621), y que con el mismo título escribió Diamante una fiesta-zarzuela que apareció impresa en la Parte XXVI (1667) de comedias escogidas. Todavía restan dos autos sacramentales más de idéntico título, ambos representados en Sevilla y documentados por Sánchez Arjona: el primero es de Juan Durán de Torres y se hizo para el Corpus del año 1642; el segundo es de Fernando Díez de Leyba y se montó en el Corpus de 1657 (al parecer no se conserva ninguno de los dos textos). Ver más detalles en la edición del auto de Arellano, Oteiza y Zugasti, 2000, p. 34.

${ }^{3}$ Remitimos para más detalles a la introducción de la edición del auto (2000, pp. 10-36 y 71-75).

${ }^{4}$ Año que para Cruickshank (1971) es el más plausible. Para otras fechas propuestas, ver Cotarelo, ed. 2001, p. 300; Valbuena Prat, introducción a Obras completas III. Autos sacramentales, Madrid, 1991. La primera edición es de 1952; Hilborn, 1938, pp. 91-94.

${ }^{5}$ Su panorama textual, complejo como en la mayoría de los autos calderonianos, se resume en una quincena larga de manuscritos de relativo interés textual y un autógrafo, con fecha escrita en la portada por otra mano más tarde, que Calderón preparó, junto con otras copias en limpio, con la intención de continuar la publicación de sus autos después de la Primera parte de 1677 (Madrid, Fernández de Buendía). Esta edición conoce dos reediciones posteriores que han sido estudiadas por Wilson, quien señala con acierto que son «a page-for-page reprint of the edition of 1677». La primera es la hecha por García Infanzón en Madrid, 1690; y la segunda, también en Madrid, por Ángel Pascual Rubio fechada en 1715 (ver Wilson, 1959). 
taculares. Según Valbuena ${ }^{6}$, El laberinto del mundo pertenecería a los autos de la segunda etapa, de 1648 a 1660, donde concurren piezas más extensas y de una puesta en escena más refinada.Y el segundo, con la estructuración de la alegoría a partir de una historia mitológica mediante el uso reiterado de la etimología «fingida».

Ambos textos, separados por unos quince años, presentan particularidades muy llamativas. Es difícil dilucidar si Calderón tuvo tan presente el texto tirsiano como para llevar a cabo su propia reescritura del mito. El sustrato real de la fábula mitológica era muy conocido y es poco rentable buscar una dependencia textual entre los dos autos (siendo ambos textos muy diferentes). Nos limitaremos por tanto en lo que sigue a señalar las diferencias y los contrastes en algunos puntos que son representativos de sus técnicas alegóricas y dramáticas.

El laberinto de Creta de entrada ha despertado pocas simpatías y valoraciones negativas debidas a la elección tirsiana de una historia mitológica para el argumento 7 . Pero se trata de un juicio crítico errado en tanto que la mitología es un campo especialmente apto para la aplicación de la alegoría sacramental y lugar común en otros dramaturgos, como el mismo Calderón ${ }^{8}$. En relación con esta supuesta inadecuación de la materia mitológica se aducen otras cuestiones ancilares relativas a la desviación interpretativa que ofrecen ciertos personajes: su ambigüedad interpretativa ${ }^{9}$ y su posición anacrónica (adelantamos

${ }^{6}$ Ver Valbuena Prat, introducción a Obras completas III. Autos sacramentales, Madrid, 1991. Para un comentario crítico a la labor editorial de Valbuena Prat, ver Arellano, $2000 b$.

${ }^{7}$ Arias, 1980, p. 126: «Tirso dramatizes the classical legend withouth beign able to mold it into a convincing allegory»; Wardropper: "The scrupulous adherence to a legend, whose inadequacy as a vehicle for the eucharistic dogma is evident, deprives the work of its value as a sacramental play» (citado por Arias, 1980, p. 126); B. de los Ríos: «No logramos imaginarnos con claridad cómo entendería el público asistente a las fiestas del corpus los pasajes simbólicos envueltos en ese espeso ropaje mitológico-histórico, con gran mezcolanza anacrónica» (Tirso, Obras dramáticas completas, III, p. 1299).

${ }^{8}$ Sobre técnicas calderonianas en general, ver Arellano, 2001a; el funcionamiento de la mitología como plano historial se aclarará más consultando Arellano, 2001b.

${ }^{9}$ En cuanto a las anomalías residuales de la ambigüedad y el anacronismo cabe apuntar que proceden de las malas interpretaciones críticas, no del texto en sí (aunque otro asunto distinto como se verá es si dan o no cohesión estructural al auto), o de las reglas genéricas intrínsecas al auto sacramental donde el mecanismo alegórico no se sujeta a tiempo ni espacio. 
que el concepto de «anacronismo» que utiliza Blanca de los Ríos no es operativo $)^{10}$. Sin embargo no se encuentra ningún rastro de inadecuación de la materia alegorizada en los pocos estudios que hay sobre el auto calderoniano de El laberinto del mundo. Ni Albert, Voght, Bacigalupo, Flasche, Navarro González o Körner ${ }^{11}$ señalan ningún tipo de incompatibilidad con la materia mitológica. En puridad, nada hay en esta materia que se oponga a su uso como argumento de un auto sacramental. El propio Calderón, como se sabe, en el prólogo a la Primera parte de sus Autos sacramentales (1677) distinguía con claridad el "argumento» del «asunto» ${ }^{12}$. Pero recuérdese que Calderón sigue en sus autos la interpretación habitual en la época ${ }^{13}$ de que las leyendas mitológicas reflejan perdidos y semiolvidados restos de la revelación verdadera ${ }^{14}$.

Las diferencias entre ambas autos no sólo se atienen a la disputa de la pertinencia o no de la materia mitologizada, sino que esencialmente atañen a su construcción. Ambos autos presentan dos formas de composición diferentes. La primera es esencialmente acumulativa. El laberinto de Creta usa un tenue hilo conductor, la historia mitológica, para ir enlazando diferentes episodios de carácter autónomo, con tenden-

10 Parker, 1983, pp. 66-67: «la obra de Calderón se trata de una representación fantástica, y por consecuencia, goza de toda la libertad con la que la imaginación derrumba las barreras de la experiencia ordinaria. Se trata de una "confusa idea" que posee todo el poder imaginativo de la "confusión", es decir, el poder de fundir juntos objetos y acontecimientos que en la experiencia ordinaria se hallan separados por el espacio y el tiempo [...] La Eucaristía, el symbolum unitatis, reúne en su unidad intemporal la totalidad del destino y la historia espiritual del género humano». Hay que matizar estas afirmaciones de Parker, discutidas y aclaradas por Arellano, 2000a, y «El marco historial», 2001b, quien enfoca de otro modo más certero el manejo del tiempo y espacio en los autos.

${ }^{11}$ Ver por este orden Albert, 1882; Voght, 1975; Bacigalupo, 1981; Flasche, 1981; Navarro González, 1987, pp. 161-162 o Körner, 1991. Más detalles bibliográficos en Arellano, 1994.

12 «Siendo siempre un mismo asunto, es fuerza caminar a su fin con unos mismos medios... [pero] estos mismos medios, tantas veces repetidos, siempre van a diferente fin en su argumento". Para estas cuestiones ver los comentarios de Arellano, 2001b, pp. 109-110.

${ }^{13}$ Presente en el Teatro de los dioses de la Gentilidad del P. Baltasar de Vitoria. Citado por Arellano, 2001b, p. 110.

${ }^{14}$ Ver Kurtz, 1991, cap. 2 «Myth and Truth». Citado por Arellano, 2001b, p. 110. 
cia multiplicadora ad infinitum al menos desde un punto de vista teórico. Este esquema compositivo por acumulación desarrolla potencialmente una nutrida presencia en escena del juego teatral, pero adolece de una aplicación constante y completa de la alegoría (que en el fondo era lo que la crítica censuraba en el auto tirsiano, más que la inadecuación de la materia mitológica en sí). En cambio, Calderón pone en escena una nueva estética no acumulativa sino sincrética, donde los modos reales y divinos de la alegoría se cohesionan con fuerza desde el principio, a través de un tema musical recurrente. La diferencia entre ambos modos de hacer es más artística que un juicio de valor. El auto de Tirso

no es tanto "enigmático», como los estudiosos suelen apreciar, sino ejemplo, más bien, de una fórmula todavía no resuelta, compuesta por elementos de distinta índole que conservan cierta autonomía: Calderón logrará que todos estos elementos se ordenen rigurosamente para construir edificios perfectamente equilibrados en sus dos vertientes, la historial y la alegórica $^{15}$.

$\mathrm{Y}$ ¿en qué se concretiza ese paradigma compositivo acumulativo en Tirso? A todas luces en una marcada fragmentación de la fábula en episodios a veces muy desligados de la trama central; en una búsqueda en la variedad de tonos, registros lingüísticos y estructuras métricas; y en una exposición de la alegoría no continua y ascendente sino con tendencia también a lo fragmentario, consecuencia, en parte, de la falta de coherencia en las equivalencias de los planos reales y alegóricos.

La vertiente argumental y estructural con tendencia a la dispersión, por ejemplo, es visible a poco que se preste atención a los principales pilares argumentales del auto tirsiano. Se abre la escena con la presencia del rey Minos que relata triunfal sus victorias sobre megarenses y atenienses, intercalando en su discurso exultante un paradigma microtextual común que es la loa de la ciudad de Creta (una muy convencional laus civitatis). Sigue la aparición de un personaje, el Tudesco, que se declara enemigo de Minos, que dialoga con Dédalo, narrador prolijo del nacimiento del Minotauro y la construcción del

\footnotetext{
${ }^{15}$ Ver la ed. de Arellano, Oteiza y Zugasti, 2000, p. 36.
} 
laberinto como prisión del monstruo. Después aparece en el tablado el rey de Etiopía, opuesto a Minos y al Minotauro. Sigue luego un interludio cómico protagonizado por el rústico Risel, cuyo engarce con la historia mitológica consiste en ser uno de los elegidos para servir de alimento al morador del laberinto. Aparece a continuación Ariadna, prisionera de Minos, acompañada de Floriso, trasunto de la Esperanza, que se enamora súbitamente de un misterioso joven dormido, Teseo, que ha llegado como navegante perturbador para acabar con el imperio de Minos. Al cortejo alegórico de ambos le sucede otro interludio cómico de Risel, donde interviene el propio Minotauro. El auto se cierra con el esperado desenlace: el triunfo de Teseo sobre el Minotauro y Minos, y bodas místicas entre Teseo y Ariadna. Al final de la pieza hay una especie de explanación final en forma de glosa con unas rudimentarias explicaciones escénicas (a la manera de unas memorias de apariencias).

En esta órbita poco integradora las figuras del Tudesco y del rey etíope han despistado a críticos como Mettmann ${ }^{16}$, y la propia Ortuño - la única que se ha ocupado con cierta dedicación de los autos tirsianos-, que han querido buscar una identificación demasiado exacta o precisa, sin tener en cuenta todos los detalles del contexto. La identificación que hace Mettmann — aceptada al fin por Ortuñodel Tudesco con la Alemania protestante, es, por ejemplo, inaceptable, entre otras cuestiones porque el texto dice justo lo contrario. Konan ${ }^{17}$, por su parte, confiesa su desorientación, y renuncia directamente a ofrecer una interpretación satisfactoria. Sin embargo la claridad del texto es meridiana. Ese Tudesco se opone desde el principio a Minos. Se enorgullece de haber postrado «en las regiones frías del Bóreas los cuellos de sus héroes", y su cara y cabellos son comparados con los rayos del sol y de la blancura más pura. Teniendo en cuenta que Bóreas y Aquilón son conceptos análogos para referirse al viento del norte, al que se opone el Austro, o viento benigno del sur, cabe relacionar a este Tudesco como defensor del bien. A lo que hay que añadir que Dédalo, opositor en escena de este Tudesco, le profetiza una suble-

16 Ver en Ortuño, 1973, pp. 133-134.

${ }^{17}$ Ver Konan, 1976, p. 271: «il demeure incertain le sens métaphorique du roi de Étiopia, du tudesque Grisón, de Fileno, Floriso et même Minos, de Dédalo et de Atenas $[\ldots]$ nous ne pourrons pas faire une interprétation correcte et concluante de cette pièce». 
vación del enemigo Grisón, esto es, de las regiones protestantes del Norte de Europa ${ }^{18}$. Por otro lado, el rey de Etiopía, que aparece a lomos de un camello, se construye como antítesis del Tudesco en el plano descriptivo, alcanzando una especie de representación de las distintas naciones del mundo, enfrentadas al mal focalizado en el rey Minos. La elaboración simbólica del personaje es más opaca que la anterior, aunque guarda estrecha relación con los motivos de Salomón y la reina de Sabá ${ }^{19}$. Sin tener un referente concreto, Tirso lo dibuja como otro paladín más del bien.

De igual forma las escenas cómicas tampoco parecen estar muy integradas, dado además que se pergeñan desde la perspectiva contemporánea de un espectador (o lector) del siglo XVII. En parte porque el discurso de Risel entra de lleno en la sátira costumbrista de la época con jocosas referencias a los sastres, taberneros, bodegoneros..., a veces bastante ingeniosas al comparar la tarasca con el Minotauro (pues si una quita las caperuzas de los aldeanos ${ }^{20}$, el otro hace lo propio con las cabezas de sus víctimas), o al relacionar el inextricable laberinto con los no menos inextricables guardainfantes o calzas atacadas. Es más, desde la perspectiva del juego escénico, la segunda intervención del personaje es una suerte de entremés donde el rústico arrimado a un árbol ${ }^{21}$ sufre las acometidas del furioso Minotauro.

${ }^{18}$ Los enfrentamientos en el Siglo de Oro en la región de los Grisones, bajo dominio protestante, pero con parte de población católica, conflictos en los que interviene el papado, España, El Imperio y Francia en el valle de la Valtelina, habitado por campesinos italianos católicos, vasallos de los grisones protestantes (ver Arellano, Oteiza, Zugasti, 2000, pp. 25-26), y Elliott, 1990, pp. 83, 93, 231, 233, 377, 453...

${ }^{19}$ La elaboración simbólica del personaje recoge la tradición que señala cómo la reina de Sabá llevó la ley escrita o antigua a Etiopía y el compromiso de enviar cada año un cordero para su oblación en el templo hierosolimitano, como recoge Calderón en su auto El cordero de Isaías. Sabá tuvo un hijo con Salomón que los etíopes consideran como fundador de la dinastía que los ha gobernado, rey que sigue la ley de Moisés, pero que está dispuesto a aceptar la ley de Gracia (ver las excelentes notas de los editores al auto tirsiano, s. v.).

${ }^{20}$ Conocida es la cita de Covarrubias en su Tesoro, con respecto a la tarasca: «una sierpe contrahecha que suelen sacar en algunas fiestas de regocijo. Díjose así porque espanta a los muchachos [...] Los labradores, cuando van a las ciudades, el día del Señor, están abobados de ver la tarasca, y si se descuidan, suelen los que la llevan alargar el pescuezo y quitarles las caperuzas de la cabeza, y de allí quedó un proverbio de los que no se hartan de alguna cosa que no es más echarla en ellos que "echar caperuza a la tarasca"». 
La variedad de tonos y registros lingüísticos, relacionada con la estructuración métrica, busca en cierta manera adquirir valor contrastivo, pero en realidad refuerza la tendencia de individualizar los distintos episodios más que marcar un hilo conductor coherente.

En general, el tono expresivo - como no podía ser de otra manera- está asociado a la forma métrica que utiliza. Entre un amplio abanico de posibilidades podría situarse las intervenciones del rústico Risel en redondillas y romance frente al tono altisonante de las décimas iniciales puestas en boca de Minos con una culta elaboración de clara impronta petrarquesca, o la declarada solemnidad de las octavas reales, con presencia de abundantes esdrújulos que caracterizan la salida a escena del rey de Etiopía. Variedad de tonos y motivos muy del gusto barroco, asociada, en suma, a la articulación escénica de cada personaje.

Un tercer aspecto diferenciador guarda relación con la forma en que Tirso y Calderón afrontan la construcción de la alegoría. La coherencia interna de los procesos alegóricos se resiente en Tirso, en parte, por la dispersión aludida líneas arriba, que discurre ajena al eje central de la historia del laberinto que pierde así su papel preponderante. No es el objeto de estas páginas realizar un estudio exhaustivo y detallado de la construcción alegórica en su conjunto, por lo que nos detendremos en dos elementos que consideramos importantes a la hora de presentar cómo procede Tirso (y que son radicalmente diferentes en Calderón). El primero explicita la construcción de la alegoría a través de la superposición lineal consecutiva de los planos historiales (aquí mitológicos) y el plano divino de la exégesis transcendente. En Calderón ambos planos convergen en solo uno. Pero en Tirso se da una suerte de mecanismo alterno de pequeños microtextos. En el ejemplo que sigue, vv. 61-100, jayanes, curetes, y titanes, en su uso historial y mitológico pasan a convertirse, como secuaces de Minos, en los ángeles caídos liderados por Lucifer que se levantaron contra Dios; mientras que el relato mitológico de los megarenses y de Scila, hija del rey Niso, cuyo cabello (el del rey, púrpura o de color oro, según la tradición) le confería la invencibilidad, y en el que se había depositado la seguridad del reino, se asemeja a la idea muy repetida en

21 «Acométele y huye por el tablado, y luego anda alrededor de un árbol que ha de haber, y el monstruo tras él dando golpes en el tronco» (v. 1165acot.). 
los Padres de la Iglesia de que la sangre de los mártires fortifica y mantiene la fe 22 :

\author{
Este es mi reino, este Creta, \\ patria de aquellos jayanes, \\ ya Curetes, ya Titanes, \\ que mi dominio sujeta. \\ Los que al son de la trompeta \\ de mi voz, inobediente \\ apenas en el oriente \\ de sus instantes primeros, \\ desnudaron los aceros \\ contra el mismo Omnipotente, \\ éstos y yo hemos vencido \\ cuanto esos golfos abrazan. [...] \\ Reinaba en Megara Niso, \\ y en un cabello fatal \\ fundaba el trono inmortal \\ que perdió su poco aviso; \\ en sólo un cabello quiso \\ que su reino eternizase \\ el hado, y que éste imitase \\ de la púrpura al color, \\ el cual, cortado, al rigor \\ caduco se sujetase. \\ Significábase en ello \\ la vigilancia en la fee, \\ tan delicada que esté \\ en lo sutil de un cabello \\ purpúreo, encendido y bello, \\ porque la fee, toda llama, \\ sangre en las aras derrama, \\ y por su conservación \\ mil héroes dieron blasón \\ al martirio y a la fama.
}

22 Es frecuente la mención de la sangre de los mártires como semilla o riego de la Iglesia y de la fe: la imagen primera al parecer es de Tertuliano, pero en San Agustín se reitera mucho, identificando esta sangre tanto con la semilla como con el riego (remitimos a la nota pertinente en la edición de Arellano, Oteiza y Zugasti, 2000, donde el lector hallará mayores detalles y ejemplos de esta cuestión). 
El segundo elemento se relaciona con la mecánica precisa de las etimologías «fingidas», que como se explica a continuación Calderón desarrolla en su auto en cantidad y Tirso sólo emplea con Teseo en la conclusión de su texto, cuando realmente ya no hace al caso usarla como bisagra del mecanismo alegórico: «Teseo tengo por nombre, / que si en Grecia Dios y Theos / es lo mismo, sincopado, / ser Theos lo que Teseo» (vv. 1304-1306).

En El laberinto del mundo de Calderón la dispersión estructural señalada en Tirso desaparece. Desde el inicio se observa una integración consciente de toda la materia alegórica ${ }^{23}$, y una cohesión en la arquitectura dramática dirigidas por dos ejes rectores: uno, las abundantes etimologías fingidas que apuntalan las vías de conexión entre mitología e historia transcendente - lo interesante de esta etimología, vista como la llave que abre la materia mitológica a la interpretación alegórica, es su constante presencia y su vinculación con todos los personajes del auto (y no sólo con el Teseo tirsiano)—; y dos, en estrecha relación con la estructura y la métrica, el principio vertebrador de las intervenciones musicales. Comentaremos brevemente ambos ejes estructuralizadores.

El texto calderoniano arranca con la irrupción en escena de un carro que representa una galera, símbolo del mal, gobernada por el Furor y la Envidia, que traen al hombre cautivo ${ }^{24}$. Esta nave que lucha contra los envites de la tormenta no es otra que la encargada de llevar a los cautivos al laberinto del mundo para que sirvan de alimento a la bestia que mora en su interior. La descripción pictórica de la nave con sus ondas llameantes, dragones y serpientes indica que se trata de una representación del demonio, del mal, en la figura del Furor que se erige, como él mismo se designa, en pirata de estos mares y siguiendo con las alusiones bíblicas, en «bestia del mar», imagen ins-

${ }^{23}$ Ver Escudero Baztán, 2012. Lo que sigue es un resumen muy breve de lo expuesto en ese trabajo.

24 «En el primero carro que será una galera negra sobre ondas de llamas, pintados sus gallardetes de dragones, y por quilla de su proa una serpiente, aparecerá en la proa el Furor, junto al árbol mayor la Envidia y al remo en una banda el Hombre de cautivo, y en otra la Malicia y otros cuatro forzados, dos a cada lado, y mientras se representan los primeros versos, da vueltas al tablado" (acot. inicial). 
pirada como muchas otras en el Apocalipsis de San Juan ${ }^{25}$. En un juego de contrastes consciente en la función catequética del texto, en igual tribulación marina se presenta a continuación otra nave, que simboliza el bien, adornada con hostias y cálices ${ }^{26}$. Este segundo carro trae la presencia de un extranjero desconocido (Teos) cuyas numerosas alusiones señalan su origen divino. Acompañado de la Inocencia vencerá a la tormenta con la convicción de que su nave navega al «norte de una estrella» que es «intacta, pura, clara, limpia y bella» (identificación mariana). Ya en tierra Furor y Teos, la acción narrativa se focaliza en la aparición de dos personajes alegóricos que con idéntico paradigma constructivo de finalidad catequética, pero basados en un juego de presencias contrarias, continúan aportando datos sobre la identidad de ese joven extranjero. Mientras la Mentira espera la llegada de la galera del furor de la Culpa, la Verdad hace lo propio con esa nave de vela blanca alimentada por el austro (viento que identifica Calderón con la divinidad, relacionado con el Espíritu Santo en numerosos lugares de la patrística, y la casa de Austria ${ }^{27}$ ) que será portadora del trigo (léase pan eucarístico) triaca contra el pestífero veneno del monstruo que habita el laberinto (vv. 222-227).

Se produce entonces en este contexto la primera de las bisagras etimológicas que utiliza Calderón para identificar ambos planos, y señalar la correlación perfecta entre la historia de la salvación y la fábula mitológica de Ariadna y Teseo. Incluso, reforzando la trama de la elaborada formación catequética, es la propia Verdad la que alude al proceso mismo de funcionamiento del propio mecanismo (vv. 242246), para establecer a continuación la etimología que permite identificar a Ariadna con la Mentira y a Fedra con la Verdad (vv. 247$269)^{28}$. Es obvio que la etimología es, en sentido riguroso, falsa, pero aquí a Calderón le interesa una elaboración ingeniosa, una especie de

25 «Alguien que bestia del mar me llama», dice el texto en v. 12 (todas las citas están tomadas de la edición de Escudero Baztán, en preparación).

26 «Da vuelta la nave que estará fundada sobre ondas de nubarrones azules y flámulas encarnadas con hostias y cálices, y vese en la popa Teos de galán, la Caridad en el árbol mayor, y la Inocencia en la proa, y los músicos de marineros» (acot. tras v. 72).

27 Sobre este tema ver el excelente estudio, ya clásico, de Rull, 1983. 
verosimilitud de concepto sutil, una amalgama lingüística que no es sino una proyección de una etimología hebrea sobre el nombre griego Ariadna (hija de Minos) y juego disociativo a partir de las voces hebreas Arie, 'león', y Adona, 'señora', enfatizando así el carácter despiadado de la Mentira. La sucesión posterior de distintos avatares lleva al Hombre cautivo a encontrarse con la Verdad. Su llanto no sólo conmueve a los habitantes donde mora el monstruo del laberinto, sino que sirve como prueba de su arrepentimiento, de su acto de contrición necesario para obtener su perdón y que será el armazón sobre el que se desarrolla a partir de ahora el auto hasta su conclusión final, y sobre el que el dramaturgo sigue diseminando las marcas identificativas de los planos alegóricos y real. En relación con la acción anterior es ahora Teos e Inocencia quienes topan con la Verdad, que vuelve a inquirir sorprendida sobre la presencia de ese extranjero que la Culpa, léase Furor, no conoce. La alusión de nuevo al mercader de trigo señala entre líneas el carácter divino de su interlocutor, apuntado con sutileza por la recurrente idea de la unión de las dos naturalezas humana y divina de Cristo que se resuelve en la segunda etimología por contaminación deriva tiva entre Teos y Teseo ${ }^{29}$ (vv. 562-577). A la que sigue una tercera, de nuevo muy ingeniosa, a través del juego de palabras que identifica el conjunto de la creación con Creta (vv. 592-599). Sobre esta Creta, o fábrica inferior, se suma una cuarta etimología que identifica al Mundo con Minos a través de la proyección de una etimología hebrea sobre un nombre griego para ajustar el tema pagano al cristiano mediante el nombre hebreo ${ }^{30}$ (vv. 624-632). A partir de este momento sólo queda buscar la correspondencia simbólica entre la imagen real del Minotauro y su proyección alegórica. En estricto sentido no se trata de otra nueva etimología denotativa, sino más bien de un proceso metafórico que identifica de manera global al monstruo alegórico con el carácter teratológico de ese otro monstruo mitad toro, mitad hombre, a partir de una estructura nominal aproximativa que bebe de fuentes patrísticas, configurando, así, un bestiario alegórico aplicado al demonio ${ }^{31}$ :

28 Para esclarecer el sentido de estas etimologías resulta muy útil el estudio de Reyre, 1998.

${ }^{29}$ Ver Reyre, 1998, s. v.

${ }^{30}$ Ver Reyre, 1998, s. v. 
serpiente, Moisés, la llama, por su astucia y su cautela David, basilisco y áspid, sobre quien el justo huella; Pedro rugiente león, que devora cuanto encuentra; hambriento lobo, Mateo; Ambrosio, traidora hiena; rabioso perro Augustino

Que en un plano visual termina con dar, a modo conclusivo y aglutinador, con la hidra de siete cabezas $^{32}$.

La aparición en escena del tercer carro, con forma de cárcel, añade a la escena el último elemento que aún quedaba suelto. Cobra así el laberinto ahora protagonismo, convertido en una fábrica desordenada donde encerrar al hombre ${ }^{33}$. Hasta aquí Calderón ha establecido con maestría y precisión todos los mecanismos que permiten leer la fábula mitológica en clave alegórica de la historia de la salvación del género humano. Su desarrollo posterior sigue punto por punto el triunfo de Teseo sobre el Minotauro gracias a la ayuda de Fedra en este caso (una curiosa desviación de la fábula). Lo que fundamenta a partir de ahora el texto es la presencia constante de Teseo, o Teos (o Cristo desde la perspectiva alegórica). Su poder celestial le lleva en su encuentro con el hombre cautivo a poder romper las cadenas que lo mantienen prisionero (vv. 1104-1108). Pero como la culpa del hombre es infinita, la acción de ese Teos, Dios, tendrá que ser más radical. Será a través

31 Estas estructuras nominales aproximativas conforman un auténtico paradigma compositivo en Calderón. Como muestra puede verse este ejemplo de la retórica del elogio sacramental en El sacro Pernaso, vv. 1368-1383: «Pan de proposición, oblación pura / y sobresubstancial vida y dulzura, / antídoto inmortal de nuestro pecho, / memorial del amor, vínculo estrecho / de caridad, manjar del elegido, / cáliz de bendición, Dios escondido, / influencia divina / de liberalidad y peregrina / dádiva transcendente; / a Aquel, en fin, que, en culto reverente, / sacrificio incruento, / misterio de la Fe, gran Sacramento, / tan para todos que en distantes puntos, / propiciatorio a vivos y a difuntos, / de la Pasión memoria, / prenda es feliz de la futura gloria».

32 Para esta hidra de siete cabezas, ver Escudero Baztán, 2002.

33 «Llega al carro donde habrá una puerta como de cárcel, y abriéndose su reja sale la Culpa della, vestida de pieles, con un bastón» (verso tras acot. 906). 
del engaño de la Mentira que Teos se vea con las cadenas que previamente había quitado al hombre, en clara correspondencia alegórica con el sacrificio de Cristo por los hombres, paradigma bíblico que Calderón utiliza muchas veces en sus autos oponiendo el sacrificio cruento de Cristo al incruento de la celebración eucarística, de ahí que al final del auto sea necesaria la presencia de la Iglesia. Pero la Verdad acudirá en auxilio de Teos, persuadida desde el principio del auto de que ese joven y gallardo mercader de trigo prefigura una imagen salvífica y mesiánica, aproximándose de este modo el momento de la exaltación eucarística. Así, en paralelo a la fábula mitológica, la Verdad acudirá en auxilio de Teos ofreciéndole tres elementos (de inequívoco valor simbólico) para vencer al monstruo que habita ese laberinto-prisión en el que yace Teos encerrado: un panecillo (vv. 1395 y ss.); una cruz en forma de daga (vv. 1417-1419); y, finalmente, una pieza de cintas de nácar (1425 y ss.). Con estas tres armas alegóricas Teos saldrá vencedor, anunciando su resurrección y triunfo soberano sobre la carne un formidable terremoto que acabará con el Mundo por los suelos y la confusión de todos los presentes. «Pavoroso paroxismo» que anuncia la salida triunfal de un Teos-Cristo, vencedor de la muerte. La acotación describe con brillante expresión la apariencia que tiene lugar en el carro de la cárcel: «Embisten todos con el hombre, y al ir a entrarle en la cárcel, sale Teos con una cinta encarnada prendida en el costado $^{34}$. En una mano el pan y en otra la cruz. Y vestido de gala, con manto encarnado, y la Culpa ensangrentado el rostro, huyendo dél; y al caer en el suelo, se levanta el Mundo» (acot.

${ }^{34}$ La relación simbólica entre la lanzada de Cristo en la Cruz y el agua y la sangre como manifestación de los siete sacramentos se supone elaboración temprana de los Padres de la Iglesia. Los testimonios serían innumerables, y basta un rápido rastreo de las fuentes para encontrar numerosos testimonios al respecto. Para Crisóstomo y Cirilo, el agua representa el bautismo, principal sacramento de la Iglesia, mientras que la sangre representa la eucaristía. Para San Agustín, todos los sacramentos salieron del costado de Cristo. Para San Cipriano, el agua y la sangre significan el agua y el vino que se coloca en la consagración del cáliz. Para Tertuliano, con la efusión de sangre y agua Cristo instituye un bautismo doble, el sacramento y el martirio (ver L. Réau, Iconografía del arte cristiano, 1997, vol. IV, pp. 529-530). Desde el punto de vista estrictamente teatral, la simbología de la imagen se unía a la espectacularidad de una apariencia impactante para el público; la memoria de apariencias de el Primer refugio del hombre y probática piscina señala muy a las claras esto último: «Esta montaña a su tiempo se ha de abrir en dos mitades y verse dentro de ella una fuente cuyo remate ha 
tras v. 1621) ${ }^{35}$. Pero malherida recuerda que pese a la muerte de la culpa original la actual queda todavía sin remisión, estableciendo así Calderón una asentada diferencia teológica entre la culpa actual que es el pecado personal cometido por cada individuo, y el original que es el común heredado de Adán ${ }^{36}$. Para combatirlo de nuevo, y así concluye el auto, Teos labrará un edificio, en oposición a la cárcel, que se levanta como alcázar (vv. 1680-1692). La referencia emblemática al pelícano $^{37}$, al pan eucarístico y a los niños de Pasión ${ }^{38}$ cierra el auto con la apoteosis de la presencia del cuarto carro $^{39}$ que resume la victoria de Cristo-Teseo, frente al Minotauro-Culpa, y la redención del género humano (vv. 1693-1704).

de ser una cruz en que ha de estar un niño, de cuyo costado, pies y manos han de salir siete listones encarnados que den en la taza de la fuente que será a manera de cáliz» (ver Shergold y Varey, 1961, p. 151; y Escudero y Zafra, 2003, páginas dedicadas a la documentación particular del auto señalado).

35 Vencedor (vv. 1635-1648): «Como este cándido pan, / que aun no probó, le adormece / tanto, que al mortal letargo, / que sus acciones suspende, / este sangriento puñal / sus siete cervices hiere, / a cuyo horrible bramido / la Culpa acudió y la sierpe / en ella la presa hizo / con las bascas de la muerte; / y volviendo a restaurarme / en la púrpura que vierte, / el hilo de la Verdad / a nueva vida me vuelve».

${ }^{36}$ Es doctrina católica definida que todos los hombres perdieron la inocencia en el pecado de Adán y nadie hubiera podido levantarse sin la gracia de Dios misericordioso (como comenta Denzinger en El magisterio de la Iglesia, 1997, párrafo 130). Más detalles en Arellano, 2011, s. v.

${ }^{37}$ Los primeros cristianos tomaron al pelícano como símbolo de expiación y redención. Según la mitología, el pelícano se abre con el pico una herida en su propio pecho para alimentar con su sangre a la cría o para dar vida a los muertos. Cristo, como el pelícano, abrió su costado para salvarnos alimentándonos con su sangre. Recuérdese que visible en el cuarto carro, el del cielo, hay un pelícano, que contrasta con el pavón, símbolo de la vanidad, que corona el carro del Mundo. Su presencia en los libros de emblemas es muy abundante, para más detalles ver cuando la serpiente envenena a los polluelos del pelícano, estos permanecen muertos tres días, pero luego el padre les da la vida derramando su sangre encima (es símbolo cristológico), según unas versiones; según otras les alimenta con sangre de su pecho. Para el pelícano ver Malaxecheverría, 1986, pp. 52-56; Portier, 1984; Sánchez López, 1991; García Arranz, 1996, pp. 627-656; Henkel y A. Schöne, 1996, cols. 811-13; y Bonardi, 1998.

${ }^{38}$ Figuras ricamente vestidas, con cruz de plata en su mano, cestillas con los atributos de la Pasión y con coronas de espinas.

${ }^{39}$ Así reza la acotación, tras v. 1692: «Ábrese el carro en que habrá un palacio y en él un pelícano, que abriéndose en dos mitades, descubra dentro del pecho, cáliz y hostia y un niño vestido de pasión». 
El esquema métrico en El laberinto del mundo tiene poca variedad polimétrica porque se subordina a un uso organizativo en la segmentación estructural. De hecho, solo tres formas métricas (silvas de consonantes pareadas ${ }^{40}$, romances y quintillas) diseñan un esquema métrico que no presta atención al desarrollo de registros diferentes. La variedad da paso en este caso a la eficiencia estructural. Lo significativo, no obstante, es notar cómo la presencia de las partes musicadas marca un Leitmotiv continuo que pone de relieve el plano alegórico, al aludir a un mensaje de esperanza y perdón para el hombre, cuyo llanto arrepentido es la llave para su salvación. Nada de esto, como se aprecia, aparece en el auto tirsiano.

En conclusión. Pocas afinidades cabe señalar entre los textos de Tirso y Calderón. Más allá de la identificación transcendente del mal con el laberinto y su monstruoso habitante, ambos dramaturgos elaboran argumentos diferentes, con valoraciones críticas dispares, y con posturas constructivas y organizativas disímiles. Tirso es más ecléctico a la hora de acumular motivos y registros. Es, en cierta medida, y dicho con cierta reserva, la poética dominante en el género sacramental hasta el monopolio calderoniano. Calderón es mucho más riguroso en la selección de los materiales argumentales, y más preciso a la hora colocarlos en un entramado alegórico levantado con no poca sabiduría dramática.

${ }^{40}$ Ver Hilborn, 1943. 


\section{BibLIOGRAFÍA}

Abert, J., «Drei Griechische Mythen in Calderóns Sacramentsspielen (I. Der göttliche Orpheus. II. Das Labyrinth der Welt. III. Der wahre Gott Pan», Jahresbericht der Königlichen Studienanstalt in Passau, Passau, 1882.

Arellano, I., Bibliografía crítica sobre el auto sacramental (col. con Á. L. Cilveti), Kassel, Reichenberger, 1994.

- «Algunos aspectos del marco historial en los autos sacramentales de Calderón», en Velázquez y Calderón. Dos genios de Europa, ed. J. Alcalá Zamora y A. E. Pérez Sánchez, Madrid, Real Academia de la Historia, 2000a, pp. 221-248.

- «Los estudios sobre los autos sacramentales de Calderón», en Estado actual de los estudios calderonianos, ed. L. García Lorenzo, Kassel, Reichenberger, 2000b, pp. 325-350.

- Calderón y su escuela dramática, Madrid, Ediciones del Laberinto, 2001a.

- Estructuras dramáticas y alegóricas en los autos de Calderón, Pamplona / Kassel, Universidad de Navarra / Reichenberger, 2001b.

- Repertorio de motivos de los autos sacramentales de Calderón, Pamplona, Servicio de Publicaciones de la Universidad de Navarra, 2011 (Publicaciones digitales del GRISO).

Arellano, I. y J. E. Duarte, El auto sacramental, Madrid, Ediciones del Laberinto, 2003.

Arias, R., The Spanish sacramental Plays, Boston, Twayne, 1980.

Bacigalupo, M. F., "The "descensus ad inferos" in Calderón's autos sacramentales», Revista Canadiense de Estudios Hispánicos, 5, 1981, pp. 249-269.

Bonardi, M. O., «Essaie d'iconographie de l'amour au XVII siècle: le pélican et le coeur», XVII Siècle, 201, 1998, pp. 639-648.

Calderón de la Barca, P., El Año Santo de Roma, ed. I. Arellano y Á. L. Cilveti, Pamplona / Kassel, Universidad de Navarra / Reichenberger, 1995.

- El indulto general, ed. I. Arellano y J. M. Escudero Baztán, Pamplona / Kassel, Universidad de Navarra / Reichenberger, 1996.

- El laberinto del mundo, ed. J. M. Escudero Baztán, Autos sacramentales completos, Pamplona / Kassel, Universidad de Navarra / Reichenberger, en preparación.

- El sacro Pernaso, introd. A. Cortijo, ed. A. Rodríguez Rípodas, Pamplona / Kassel, Universidad de Navarra / Reichenberger, 2006.

- No hay instante sin milagro, ed. I. Arellano, I. Adeva y R. Zafra, Pamplona / Kassel, Universidad de Navarra / Reichenberger, 1995.

- Obras completas III. Autos sacramentales, ed. Á.Valbuena Prat, Madrid, Aguilar, 1991, 2 a ed., 2 a reimp. Primera edición de 1952. 
Cruickshank, D. W., "The date of Calderón's El laberinto del mundo», Hispanic Review, 39, 1971, pp. 61-69.

Denzinger, E., El magisterio de la Iglesia, Barcelona, Herder, 1997.

Elliott, J. H., El Conde Duque de Olivares, Barcelona, Crítica, 1990.

Escudero BAztÁn, J. M., «El bestiario fantástico en los autos sacramentales de Calderón (I: La hidra)", en Calderón 1600-2000. Jornadas de investigación calderoniana, ed. A. González, México, El Colegio de México / Fondo Eulalio Ferrer, 2002, pp. 109-128

— "Calderón y las etimologías fingidas en El laberinto del mundo», en Ingenio, teología y drama en los autos sacramentales de Calderón, ed. M. C. Pinillos, Pamplona / Kassel, Universidad de Navarra / Reichenberger, 2012, pp. 39-54.

Escudero, L. y R. Zafra, Memorias de apariencias y otros documentos sobre los autos de Calderón de la Barca, Kassel, Reichenberger, 2003.

Fitzmyer, J. A., Teología de San Pablo, Madrid, Ediciones Cristiandad, 2008.

Flasche, H., «Más detalles sobre el papel de los cuatro elementos en la obra de Calderón. Análisis de las fuentes y del lenguaje del dramaturgo», Letras de Deusto, 11, 22, 1981, pp. 5-14.

García Arranz, J. J., Ornitología emblemática, Cáceres, Universidad de Extremadura, 1996.

Grimal, P., Diccionario de mitología griega y romana, Barcelona, Paidós, 1965.

Henkel, A. y Schöne, A., Emblemata, Stuttgart, Metzler, 1996.

Herrero, J., «The baroque as Laberinth:The Devil as Courtier in Calderón's Art», Indiana Journal of Hispanic Literatures, 1, 1, 1992, pp. 163-184.

Hilborn, H. W., A Chronology of the Plays of don Pedro Calderón de la Barca, Toronto, Toronto University Press, 1938.

- "Calderón's silvas», Publications of the Modern Language Association of America, 58, 1943, pp. 122-148.

Konan, J., "Prédestination et libre arbitre dans les autos et comedias de santos de Tirso de Molina", Annales de l'Université d'Abidjan, 9, 1976, pp. 26782.

Körner, K. H., "La función atenuadora de "en fin" en los textos de Calderón», Hacia Calderón, IX coloquio anglogermano, ed. H. Flasche, Stuttgart, Franz Steiner, 1991, pp. 9-14.

Kurtz, B., The Play of Allegory in the Autos Sacramentales of Pedro Calderón de la Barca, Washington, The Catholic University of America Press, 1991.

Leavitt, S. E., "Humor in the Autos of Calderón», Hispania, 32, 2, 1956, pp. 137-144.

Malaxecheverría, I., Bestiario medieval, Madrid, Siruela, 1986.

Navarro GonzÁlez, A., Calderón de la Barca: de lo trágico a lo grotesco, Kassel, Reichenberger, 1987. 
Ortuño, M. M., The «autos sacramentales» of Tirso de Molina, tesis doctoral de la Universidad de Michigan, 1973, UMI, 1997.

PArker, A. A., Los autos sacramentales de Calderón de la Barca, Barcelona, Ariel, 1983.

Portier, L., Le pélican. Histoire d'un symbole, Paris, Éd. du Cerf, 1984.

RÉAU, L., Iconografía del arte cristiano, Barcelona, Ediciones del Serbal, 1997, varios vols.

Reyre, D., Lo hebreo en los autos sacramentales de Calderón, Kassel, Reichenberger, 1998.

Rull, E., «Hacia la delimitación de una teoría político-teológica en el teatro de Calderón», en Calderón, Actas del Congreso Internacional sobre Calderón y el teatro español del Siglo de Oro, ed. L. García Lorenzo, Madrid, CSIC, 1983, vol. II, pp. 759-767.

SÁNCHEz LóPez, J. A., «Iconografía e icnología del pelícano: un ensayo sobre la reconversión del concepto de filantropía», Boletín de Arte, 12, 1991, pp. 127-146.

Santo Tomás, Suma Teológica, Madrid, BAC, múltiples ediciones.

Shergold, N. D. y J. E. VArey, Los autos sacramentales en Madrid en la época de Calderón, 1637-1681. Estudios y documentos, Madrid, Ediciones de Historia, Geografia y Arte, 1961.

Tirso de Molina, El laberinto de Creta, La madrina del cielo, La ninfa del cielo, en Obras completas. Autos sacramentales II, ed. I. Arellano, B. Oteiza y M. Zugasti, Pamplona / Madrid, Universidad de Navarra / Instituto de Estudios Tirsianos, 2000 (el auto ocupa las pp. 103-170).

Voght, G. M., The Mythological Autos of Calderón de la Barca, Tesis doctoral, Universidad de Michigan, 1975 (DAI, 35, 1975, 3015A-16A).

Wilson, E. M., "Calderón's Primera parte de autos sacramentales and Don Pedro de Pando y Mier», Bulletin of Hispanic Studies, 37, 1959, pp. 16-28). 